\title{
Igualdade de Gênero e Raça no Brasil: Uma Discussão sobre a Política Pública de Emprego*
}

\author{
Marcia de Paula Leite \\ Silvana Maria de Souza
}

\section{INTRODUÇÃO}

$\mathrm{O}$

s últimos dados sobre o desempenho econômico no Brasil são bastante alvissareiros. O país vem crescendo, desde 1998, a taxas próximas de $4 \%$ ao ano, em média, evidenciando uma importante tendência de um desenvolvimento sustentado. Tal tendência se explicita ainda mais a partir de 2004, quando a taxa média de crescimento passa a se aproximar dos $5 \%$. Esse crescimento veio acompanhado de um importante processo de estruturação do mercado de trabalho, com recuperação do valor real dos salários, diminuição das taxas de desemprego e das formas vulneráveis de trabalho, e crescimento do trabalho protegido.

É importante lembrar que esses dados alentadores do mercado de trabalho foram não só consequência do desenvolvimento mas também de políticas públicas de combate às formas irregulares de trabalho, como o trabalho forçado, o trabalho desenvolvido nas falsas cooperativas, o não registrado etc. Observe-se, portanto, que a melhoria do mercado de trabalho contou com políticas explícitas voltadas para a proteção de trabalhadores e trabalhadoras, tomadas tanto no âmbito do Ministério

\footnotetext{
* Este texto foi elaborado com base no relatório do projeto Políticas de Emprego e Igualdade de Oportunidades de Gênero e Raça/Etnia nos Países do Mercosul e Chile, coordenado pela Organização Internacional do Trabalho (OIT) em 2007 e em 2008.
}

DADOS - Revista de Ciências Sociais, Rio de Janeiro, vol. 53, nำ1, 2010, pp. 195 a 231. 
do Trabalho e Emprego (MTE), especialmente mediante a dinamização das ações de fiscalização, quanto no âmbito do Ministério Público do Trabalho, que, com a redefinição de seu papel na Constituição de 1988, passou a atuar mais efetivamente em ações de investigação e de encaminhamento judicial de questões relacionadas ao descumprimento da legislação, afetando, seja um coletivo de trabalhadores, seja a sociedade (Baltar, Krein e Leone, 2009:45) ${ }^{1}$.

Tal quadro, associado a programas de combate à desigualdade, como Bolsa Família, Luz para Todos, Microcrédito, entre outros, tem permitido que o desenvolvimento econômico venha sendo acompanhado da distribuição de renda e da diminuição da miséria e da pobreza, numa inflexão da tradição brasileira de crescimento econômico com concentração de renda. Como se sabe, muitas foram as quadras de nossa história em que o crescimento econômico beneficiou majoritariamente os setores menos necessitados da população, como ocorreu, por exemplo, de forma particularmente pronunciada nos anos do "milagre brasileiro", durante o regime militar ${ }^{2}$.

Esse recente processo de desenvolvimento implica, portanto, novas prioridades para as políticas públicas, voltadas exatamente para o combate à desigualdade social, o que significa atacar seus pilares básicos, dentre os quais se destacam as desigualdades de gênero e raça no mercado de trabalho. Contudo, a adoção de políticas de promoção da igualdade de oportunidades de gênero e raça são práticas recentes no país que, embora tenham sido significativas nos últimos anos, ainda enfrentam muitos desafios.

De fato, foi apenas a partir de uma denúncia encaminhada pelo movimento social à Organização Internacional do Trabalho (OIT), em 1992 sobre o desrespeito governamental à Convenção 111 (que trata da não discriminação no emprego e na ocupação), assinada pelo país desde 1965 -, que o Ministério do Trabalho, com o Ministério da Justiça e a Secretaria Nacional de Direitos Humanos, iniciou ações, a partir de 1995, para tornar efetivos os princípios dessa Convenção, a fim de dar visibilidade ao problema da discriminação; fortalecer a ação individual para promover o respeito à diversidade e à igualdade; incluir esses temas nas atividades de rotina do Ministério e de outros organismos governamentais; e treinar multiplicadores para atuar em relação à diversidade e à igualdade de oportunidades no mercado de trabalho. 
No ano seguinte, com o lançamento do Programa Nacional de Direitos Humanos (PNDH), pelo Ministério da Justiça, o governo começou a atuar mais efetivamente na formulação de políticas públicas orientadas para esses temas. Para isso, foram criados grupos técnicos, tais como o Grupo de Trabalho Multidisciplinar (GTM), dirigido para a promoção de igualdade de oportunidades no trabalho e na ocupação, formado por representantes das diversas secretarias do MTE; o Grupo de Trabalho contra a Discriminação no Emprego e na Ocupação (GTDEO), formado por representantes dos vários ministérios e secretarias de governo, sob a coordenação do MTE; e o Grupo de Trabalho Interministerial para a Valorização da População Negra (GTI), coordenado pelo Ministério de Justiça e pela Secretaria Nacional de Direitos Humanos.

Nesse sentido, pode-se dizer que é só a partir de 1996 que o governo começa a adotar políticas voltadas para a promoção da igualdade de gênero e raça. Esse fato coloca um duplo desafio às políticas públicas atuais. Por um lado, vivemos uma realidade tributária de um longo período em que essas questões foram ignoradas, e na qual as desigualdades eram ainda muito grandes; por outro, uma situação em que o país não possui um acúmulo de experiências que permita aos órgãos públicos, bem como à sociedade civil organizada, desenvolver propostas mais efetivas de promoção da igualdade de oportunidades.

Tendo em vista o curto período de tempo em que as políticas públicas dirigidas a essas questões vêm sendo implementadas no país, elas se veem diante de um conjunto de dificuldades que vão desde a reação dos setores mais conservadores até a inexperiência dos gestores em relação às diferentes possibilidades e aos caminhos mais viáveis para concretizá-las. Isso não significa, contudo, que o país não tenha dado um salto extremamente importante no que concerne à adoção de políticas de promoção da igualdade de gênero e raça.

Neste texto, nosso objetivo é analisar, especificamente, o processo de implementação de políticas de igualdade de gênero e raça na área do emprego, discutindo especialmente como elas vêm sendo tratadas pelo Sistema Público de Emprego, Trabalho e Renda (SPETR), pelos Planos Plurianuais (PPAs) do governo federal nos períodos de 2004 a 2007 e de 2008 a 2011, bem como pelas secretarias criadas precisamente com essa finalidade, ou seja, a Secretaria Especial de Políticas para as 
Mulheres (SPM) e a Secretaria Especial de Políticas de Promoção da Igualdade Racial (Seppir).

\section{A CONFORMAÇÃO DO SISTEMA PÚBLICO DE EMPREGO NO BRASIL}

Até os anos 1970, os programas do Sistema Público de Emprego no Brasil se restringiam à indenização do trabalhador demitido ou à formação de patrimônio do Fundo de Garantia por Tempo de Serviço (FGTS) ${ }^{3}$, do Programa de Integração Social (PIS) e do Programa de Formação do Patrimônio do Servidor Público (Pasep) ${ }^{4}$ (Cardoso Jr. et alii, 2006:8). Contudo, esses programas não podiam ser considerados um verdadeiro sistema público de emprego, na medida em que ele carecia de sua função principal, qual seja, a reincorporação do trabalhador ao emprego (id., ibid.). Embora a criação do Sistema Nacional de Emprego (Sine $)^{5}$, em 1975, e de uma institucionalidade voltada para a intermediação da mão de obra comece a dar forma ao sistema, é somente com a Constituição Federal de 1988 e com a criação do Fundo de Amparo ao Trabalhador (FAT) e do Conselho Deliberativo do Fundo de Amparo ao Trabalhador (Codefat), em $1990^{6}$, que será dado o passo final para a estruturação do sistema.

Com efeito, a Constituição de 1988 estabeleceu as bases para a organização de um programa de amparo ao trabalhador desempregado (o Seguro-Desemprego) que, junto com a estabilidade do financiamento, veio representar o eixo organizador de um conjunto de direitos e serviços relativos, seja às políticas passivas para o mercado de trabalho, como a assistência financeira ao desempregado, seja às ativas, como a qualificação da mão de obra e os programas de apoio a pequenos e microempreendimentos ${ }^{7}$ (Azeredo, 1998:85). O FAT possui uma importante centralidade na constituição do sistema: além de proporcionar um fluxo estável de recursos, permitiu ao sistema diversificar seus propósitos, superando a desarticulação das políticas existentes, assim como sua sujeição às variações do ambiente político.

A mais importante alteração desse quadro foi promovida em 1991, com a criação de um seguro-desemprego especial, que deveria vigorar temporariamente durante os seis primeiros meses de 1992 (id., 1998) e que ampliou os critérios de elegibilidade em termos de tempo e de público. No que concerne ao tempo, "bastava comprovar carteira assinada nos últimos seis meses", o que permitiu incorporar "aqueles trabalhadores sujeitos a maior instabilidade do vínculo empregatício e com baixa 
proteção no momento do desemprego" (Cardoso Jr. et alii, 2006:13-14). Quanto ao público, a alteração incorporou trabalhadores até então desprotegidos - "pescador artesanal, empregadas domésticas, trabalhadores libertos de condição análoga à de escravo" (id., ibid.). O seguro-desemprego especial foi sendo renovado a cada seis meses até junho de 1994, quando foi promulgada a lei 8.900, que, além de torná-lo permanente, ampliou seu raio de ação ao estabelecer que o seguro tem como finalidade "prover assistência financeira temporária ao trabalhador desempregado, em virtude de dispensa sem justa causa e auxiliar os trabalhadores na busca de emprego, promovendo, para tanto, ações integradas de orientação, recolocação e qualificação profissional" (Azeredo, 1998:95; ênfase nossa).

É importante sublinhar que o auxílio passou a estar disponível aos trabalhadores em geral, independentemente de sua condição de segurado ou não do programa. Foi a partir de então que se estabeleceram as condições para a implementação de um amplo programa nacional de formação profissional, coordenado pelo Ministério do Trabalho, as quais seriam efetivadas em 1995, com a criação do Plano Nacional de Educação Profissional (Planfor).

A grande inovação do plano consistiu não só em unificar as várias políticas de formação profissional do país como também em integrá-las à política pública de emprego, incluindo o compromisso de promover a igualdade de gênero e raça no mercado de trabalho de forma explícita em seus objetivos. Tais objetivos seriam aprofundados com a adoção do Plano Nacional de Qualificação (PNQ), que substituiu o Planfor em 2003 e não só deu um novo destaque à promoção da igualdade de gênero e raça no mercado de trabalho como também à articulação da política pública de qualificação profissional e às demais políticas de trabalho e renda, conforme veremos mais adiante.

No que concerne à igualdade de gênero, é importante destacar, contudo, que, nos dois planos, as mulheres são consideradas público prioritário a partir de sua inclusão entre os grupos vulneráveis do mercado de trabalho, fato que merece algumas reflexões. A mais importante delas consiste em que, literalmente, o termo vulnerável significa fraco, frágil, carente de proteção, o que pode ser válido para determinados segmentos do mercado de trabalho (por exemplo, os menos escolarizados, jovens em risco social, pessoas com necessidades especiais), mas não para todos. No caso das mulheres, se essa visão sustentou a adoção 
de uma política afirmativa, no sentido de estabelecer um atendimento que correspondesse, pelo menos, à sua participação na População Economicamente Ativa (PEA), também reforçou imagens e representações do trabalho feminino que pouco têm a ver com a realidade e que, ao identificar o trabalho feminino com determinadas ocupações assemelhadas ao trabalho doméstico, acabam por reforçar a tradicional divisão sexual do trabalho, que relega as mulheres a trabalhos mal pagos e pouco valorizados (Abramo, 2007; Leite e Souza, 2002) ${ }^{8}$. Assim sendo, essa concepção não facultou uma discussão mais qualificada sobre a mão de obra feminina como um setor discriminado da força de trabalho, o que teria permitido evoluir na adoção de políticas voltadas para as maneiras pelas quais essa discriminação se expressa, como o combate às formas vigentes da divisão sexual do trabalho e à segregação e segmentação de gênero no mercado de trabalho.

Nesse sentido, é apenas a partir de meados da década de 1990 que o Sistema Público de Emprego vai se conformando, ainda que de forma desarticulada e fragmentada. Visando a seu desenvolvimento, serão realizados dois congressos nacionais do Sistema Público de Emprego, Trabalho e Renda (SPETR), em 2004 e em 2005, os quais incluíram vários congressos regionais em sua preparação, envolvendo um amplo conjunto de atores sociais e de instituições governamentais e não governamentais.

Também em 1995, merece destaque a criação das Comissões Municipais e Estaduais de Emprego, que constituíram um passo fundamental para a descentralização do sistema. Às comissões, compostas de forma paritária e tripartite, foi atribuído um conjunto de tarefas, como a definição da demanda de qualificação profissional em seus territórios; o acompanhamento e a avaliação dos cursos ministrados; a elaboração de projetos de desenvolvimento local para minorar os efeitos do desemprego; o monitoramento dos projetos financiados pelo FAT; a disseminação de informações acerca do mercado de trabalho (Nabuco, Castro e Dutra apud Brasil. MTE, Codefat e Fonset, 2005:284).

O primeiro ponto que vale ser destacado na realização desses congressos diz respeito ao próprio nome conferido ao sistema. Ao substituir a ideia de Sistema Público de Emprego pela de Sistema Público de Emprego, Trabalho e Renda, ampliam-se os grupos contemplados, integrando os trabalhadores informais, os microempreendedores e os trabalhadores de empreendimentos solidários. Outra questão impor- 
tante é a ênfase na gestão participativa do sistema, centralizada nas Comissões Estaduais e Municipais de Emprego. Destaque-se ainda o fato de os congressos encamparem a ideia, já desenvolvida no Planfor, de grupos ou setores vulneráveis, elegendo como público prioritário os jovens, os trabalhadores de mais de 40 anos, as mulheres, os afrodescendentes, os desempregados de longa duração, os trabalhadores com necessidades especiais, entre outros.

O I Congresso sublinhou uma série de fragilidades no Sistema Público de Emprego: a desarticulação entre suas diferentes funções, a escassez de recursos, o acesso limitado da população, a escassez de informações sobre o mercado de trabalho, a necessidade de redefinição de suas ações, bem como a criação de novas.

No que respeita à promoção da igualdade de oportunidades, ela aparece no destaque conferido à inserção dos grupos vulneráveis. Essa preocupação se explicitará no II Congresso, que estabelece que a função de inserção dos grupos vulneráveis incorpora, além da juventude, "mulheres, portadores de deficiência, afrodescendentes, indígenas, desempregados de longa duração e pessoas com mais de 40 anos com dificuldades de inserção, entre outros" (Brasil. MTE, Codefat e Fonset, 2005:297). O II Congresso evolui no que concerne a propostas voltadas para a articulação, a descentralização e a universalização de suas ações, com seletividade voltada para os grupos vulneráveis, a participação dos atores, a integração com a escolaridade e o fortalecimento das políticas ativas.

As decisões do II Congresso sublinham a ideia de que, em face das transformações no mundo do trabalho, novas funções deveriam ser incorporadas ao SPETR, como a inserção de grupos sociais vulneráveis e a geração de trabalho e de renda por meio de ações de microcrédito.

Ressalte-se, no entanto, que não constam das resoluções do II Congresso proposições concretas de como inserir os grupos vulneráveis nas ações do sistema, assim como considerações voltadas para as especificidades de cada um deles. Nesse sentido, a inserção desses grupos aparece mais como uma orientação geral, a ser controlada a partir dos parâmetros de efetividade, eficácia e eficiência (ou seja, basicamente, a partir da proporção de pessoas atendidas, que deve ser, pelo menos, igual à porcentagem de sua presença na PEA), e como estratégia de combate à pobreza do que voltada para o enfrentamento de formas de discriminação, o que suporia políticas concretas de igualdade de 
oportunidades para cada grupo específico em cada uma das funções do sistema.

Uma segunda questão que a análise das resoluções do II Congresso levanta diz respeito à ausência da transversalização de gênero, raça e etnia, seja como tema, seja como princípio. Esses limites são explicitados na discussão a seguir, sobre as várias ações do SPETR.

\section{Qualificação: Um Passo em Direção à Igualdade de Oportunidades - O Atendimento Preferencial de "Pessoas Vulneráveis Econômica e Socialmente"}

Consoante ao já explicitado, o Plano Nacional de Educação Profissional (Planfor) inaugura, em 1995, um Sistema Nacional de Educação Profissional, unificando as várias políticas de formação profissional então existentes no país, integrando-as à política pública de emprego, trabalho e renda, e inserindo o compromisso de promover a igualdade de gênero e raça no mercado de trabalho de forma explícita em seus objetivos.

O plano se propunha a abarcar, prioritariamente, aquelas pessoas que são "vulneráveis econômica e socialmente, definindo-se o grau de vulnerabilidade em função da combinação de atributos que pudessem implicar desvantagem ou discriminação no mercado de trabalho, bem como dificultar o acesso a outras formas alternativas de qualificação ou requalificação profissional" (Brasil. MTE, 1997:7).

Aos grupos vulneráveis deveriam ser garantidos pelo menos $80 \%$ dos recursos e $90 \%$ das inscrições, além do critério de que cada um deles deveria ter participação no programa ao menos igual à sua proporção na PEA.

O Planfor consiste na primeira política adotada no âmbito das funções do SPETR em que aparece explicitamente a questão da discriminação. Ainda que restrita à qualificação e com os problemas já levantados em relação ao fato de considerarem as mulheres "vulneráveis", o plano foi um passo importante no sentido de dar visibilidade às desigualdades, sobretudo às de gênero e raça. Em 1996, a partir de um protocolo assinado entre o MTE e o Conselho Nacional dos Direitos das Mulheres, foi definido o compromisso de garantir um espaço privilegiado às mulheres, sobretudo às que estivessem em risco de pobreza, prostituição e violência doméstica, e de desenvolver um avanço metodológico e con- 
ceitual visando à incorporação da dimensão de gênero no plano em seu conjunto (Abramo e Todaro, 2002; Abramo, 2007; OIT, 2005) ${ }^{9}$.

Todavia, ainda que o Planfor tenha ampliado o campo de atuação do Sistema Público de Emprego e, ao promover a articulação com outros tipos de política, tenha engendrado uma discussão mais aprofundada em torno da desigualdade de oportunidades no mercado de trabalho, $\mathrm{o}$ fato é que havia alguns problemas inerentes à sua concepção de formação profissional.

Embora os documentos sublinhassem a formação como direito dos cidadãos e se referissem à criação de um Sistema Nacional de Formação Profissional, ao desvincular o profissional do educacional, esses preceitos sucumbiram em função de uma concepção de formação entendida como forma de adequar o(a) trabalhador(a) às necessidades do mercado. Por outro lado, ao não articular a formação com o desenvolvimento sustentável, suas ações se voltaram apenas para o treinamento do(a) trabalhador(a) para uma ocupação.

Nesse sentido, a substituição do Planfor, a partir de 2003, pelo PNQ, consistiu num passo importante na medida em que, a partir de então, a qualificação passa a ser vinculada ao "modelo de desenvolvimento", o que implicou a formulação de novas diretrizes, que contribuíram especialmente para a "superação da sua condição de política eminentemente compensatória" (Brasil. MTE, 2003:25). Não se tratando apenas de uma alteração de denominação, o PNQ amplia conceitos e promove um conjunto de mudanças nas dimensões política, conceitual, institucional, pedagógica e ética, com o objetivo de

contribuir para promover a integração das políticas e para a articulação das ações de qualificação social e profissional do Brasil e, em conjunto com outras políticas e ações vinculadas ao emprego, ao trabalho, à renda e à educação, deve promover gradativamente a universalização do direito dos(as) trabalhadores(as) à qualificação (id., ibid.:26).

A dimensão política estabelece como meta o encaminhamento das políticas públicas para o "universal como direito, porém priorizando [...] aqueles com maiores dificuldades de inserção no mercado de trabalho" (ibid.:10).

A conceitual defende a centralidade do trabalho e concebe a qualificação como uma "relação social" que é "fundamental ser negociada entre trabalhadores e empregadores" e que, simultaneamente, se configura 
como "política de trabalho, de renda e educacional" (ibid.:11), enfatizando que "as Políticas Públicas de Qualificação não se resumem a cursos. Também incluem políticas de certificação, orientação, estudos e pesquisas sobre esses processos" (ibid.).

Nessa dimensão, bem como na pedagógica, percebe-se claramente a ampliação da concepção de formação profissional: o PNQ entende a formação profissional como "qualificação social e profissional". Nesse sentido, "adquire maior ênfase a integração da Política de Qualificação com as demais Políticas Públicas de Trabalho, Emprego e Renda e com aquelas dos campos da educação e do desenvolvimento" (Brasil. MTE, 2003:25; ênfases no original). No que diz respeito à integração da qualificação profissional com as políticas educacionais, ela contempla uma mudança importante de concepção ao contrapor-se à separação entre educação básica e formação profissional. Essa integração se torna importante quando se pensa nas mudanças resultantes do processo de reestruturação produtiva que trouxeram uma "revalorização dos conteúdos próprios da educação geral em detrimento do treinamento específico" (Azeredo, 1998:262).

A dimensão institucional, por sua vez, põe em perspectiva a articulação da política de qualificação com as demais políticas públicas de emprego, trabalho e renda. Nesse sentido, não se trata somente de "estabelecer estratégias de curto, médio e longo prazo, em função da configuração do mercado de trabalho e da PEA", mas "de se contrapor à noção de qualificação como algo estritamente individual e derivado das exigências dos postos de trabalho", identificando-a "[...] como um fator de inclusão social, de desenvolvimento econômico, com geração de trabalho e distribuição de renda" (Brasil. MTE, 2003:5 e 11).

A dimensão pedagógica problematiza a carga horária, e o PNQ estabelece o parâmetro de 200 horas, ao passo que, no Planfor, a carga horária média era de 60 horas.

Por fim, a dimensão ética se debruça sobre as "denúncias" de improbidade do Planfor no que diz respeito à distribuição dos recursos e à prestação de contas, chamando a atenção para a necessidade de transparência na gestão dos recursos e de um efetivo controle social.

A política de qualificação proposta pelo PNQ traz à tona outro conceito de qualificação profissional, entendendo-a como um processo permanente, cujo objetivo é promover a inclusão social e contribuir para a re- 
dução das desigualdades sociais por meio da eliminação dos obstáculos - informados pelo gênero, pela geração, pela raça/cor, pela etnia etc. - ao acesso dos(as) trabalhadores(as) às oportunidades de emprego, trabalho e renda.

Como já analisamos anteriormente (Leite e Souza, 2005), o PNQ avança no que concerne à inclusão da dimensão de gênero e raça/etnia ao ultrapassar a meta numérica de incorporação e a concepção restrita de "experiências inovadoras" do Planfor. O principal avanço consiste na compreensão de que as dimensões de gênero e raça / etnia deveriam estar presentes em todos os cursos, e não apenas nos dirigidos às mulheres ou aos afrodescendentes. Essa nova definição exigiu esforços para desenvolver metodologias e qualificar instituições executoras, além dos próprios gestores. Dentre as medidas tomadas se destacam as de capacitação em gênero e raça dos gestores encarregados da coordenação do PNQ nos estados e municípios selecionados, executadas em parceria com a OIT por meio do Programa de Fortalecimento Institucional para Igualdade de Gênero, Raça, Erradicação da Pobreza e Geração de Emprego (GRPE) (Abramo, 2007:309).

No que tange à eliminação dos obstáculos ao acesso dos(as) trabalhadores(as) às oportunidades de emprego, trabalho e renda, expresso nas metas quantitativas, o PNQ evidencia um avanço para todos os grupos da população considerada vulnerável, exceto o grupo dos(as) trabalhadores(as) com escolaridade inferior ao ensino médio, para o qual a cobertura se encontra abaixo de $100 \%$, indicando que o programa não foi socialmente efetivo ao longo do período de 2003 a 2006.

Quanto ao avanço conceitual, o Trabalho Doméstico Cidadão é um dos exemplos que, por seu caráter inovador, vale a pena ser destacado. Implementado em 2005, tem como objetivo "valorizar o trabalho e a trabalhadora doméstica rumo a uma política de Estado [...] para torná-lo [o Trabalho Doméstico Cidadão] uma política permanente". Trata-se de relacionar o trabalho doméstico "com direitos plenos" e promover seu reconhecimento "como profissão" (Brasil. MTE, 2005:14). A experiência que embasa o programa foi realizada em 1999, na Bahia, sob a responsabilidade do Sindicato das Trabalhadoras Domésticas desse estado. Essa experiência, "acrescida de inovações conceituais e metodológicas das entidades parceiras e do MTE", resulta "na primeira iniciativa de governo exclusivamente voltada para as trabalhadoras domésticas na História do Brasil" (id., ibid.:10 e 12). 
É importante assinalar, contudo, que o PNQ também apresenta um conjunto de limitações. De acordo com Sardenberg e Costa (2006) e Abramo (2007), elas se concentram na questão da transversalização.

Embora o plano insista na necessidade da transversalização, ele carece de instrumentos para sua efetivação, tais como: mecanismos explícitos de incorporação do público prioritário; estímulos diferenciados para atender às especificidades de cada grupo; programas de qualificação em ocupações não tradicionais para mulheres e negros; indicadores adequados para a geração de informações sobre gênero e raça; novos postos em ocupações não tradicionais; políticas especiais para facilitar a participação das mulheres, como creches, bolsas de auxílio e restaurantes populares; instrumentos adequados e de fácil acesso para que as organizações de mulheres e de outros grupos discriminados tenham acesso aos recursos do FAT. De acordo com Sardenberg e Costa (2006), o plano e a transversalização deveriam dar início à disseminação de metodologias, práticas e conteúdos inovadores que pudessem subverter a divisão sexual do trabalho e a tradicional classificação entre ocupações femininas e masculinas, proporcionando "a integração de novos perfis de trabalhadores, estimulando a demanda, a partir da oferta de trabalhadores mais capacitados ou a contratação de trabalhadores tradicionalmente excluídos" (ibid.:15).

\section{Sistema de Intermediação de Mão de Obra}

Como as demais funções do Sistema Público de Emprego, Trabalho e Renda (SPETR), a intermediação também foi instituída tardiamente no país (em 1975), e seu desenvolvimento, até o início dos anos 2000, se deu de maneira desarticulada em relação aos demais programas do sistema (IE/Cesit/Unicamp, 2005:282). Nesse sentido, a ampliação de suas atribuições e sua vinculação com os demais programas do SPETR ocorreram basicamente a partir do II Congresso do SPETR. De fato, é a partir de então que o sistema passa a considerar que

[...] é fundamental reforçar os mecanismos que condicionam o acesso ao auxílio financeiro temporário por condição de desemprego à inscrição na intermediação, orientação, qualificação social e profissional, certificação profissional, bem como a programas de geração de emprego, trabalho e renda, facilitando a reinserção no mercado de trabalho ou em oportunidades de geração de renda (Brasil. MTE, Codefat e Fonset, 2005:296). 
De acordo com suas resoluções, a função de intermediação deveria realizar-se, portanto, pela captação de vagas junto ao mercado de trabalho e por formas alternativas de geração de trabalho e renda. A fim de garantir mais eficiência na captação de vagas, propõe-se que sejam realizadas ações de divulgação e sensibilização, visando a que se reduza a discriminação de grupos vulneráveis (id., ibid.).

Os princípios relativos à captação de vagas no mercado de trabalho, no que concerne aos grupos vulneráveis, estabelecem: que o Sistema Nacional de Emprego (Sine) se norteará pela adoção do princípio de focalização, reconhecendo o necessário atendimento específico a ou focalizado em grupos vulneráveis mais ameaçados pelo desemprego e com maior dificuldade de inserção no mercado de trabalho; que os planos de trabalho a serem apresentados pelos executores das ações integrantes do Sine devem conter as metas de execução física relativas à intermediação de mão de obra para as mulheres com escolaridade até o segundo grau, entre outros grupos vulneráveis; e que 15\% dos recursos de intermediação e orientação profissional serão distribuídos com base na participação dos grupos vulneráveis em relação ao total de trabalhadores desempregados.

Em 2006, 212.476 mulheres foram atendidas pelo Sine, correspondendo a $53,4 \%$ do total de trabalhadores recolocados. Embora esse número atinja a meta de atender às mulheres pelo menos na proporção de sua presença na PEA, não expressa o atendimento nas atividades de geração de emprego e renda e economia solidária, programas nos quais a incorporação da dimensão de gênero quase não aparece, conforme veremos a seguir. Convém destacar ainda que o programa praticamente não apresenta orientações voltadas para a intermediação da população afrodescendente.

\section{Programa de Geração de Emprego e Renda (Proger)}

Criado em 1994, o Proger surge com o objetivo de oferecer alternativas de inserção no processo produtivo por meio de estímulos à capacidade empreendedora e à busca de autossustentação do empreendimento. $\mathrm{O}$ programa propõe, nesse sentido, a concessão de linhas especiais de crédito, direcionadas a empreendedores tanto no setor rural quanto no urbano, inclusive agricultores familiares, e a suas cooperativas e associações de produção. Contempla ainda os empreendedores de baixa renda, que buscam, na informalidade, o sustento próprio e o da famí- 
lia, financiando o autoemprego como alternativa de minimizar os efeitos do desemprego prolongado. O Proger não se restringe, contudo, à concessão de crédito; abarca também a capacitação gerencial do beneficiário, o acompanhamento e a assistência técnica.

Buscando evitar critérios que dificultam a liberação de crédito para o público beneficiário, formado especialmente por pequenos tomadores, foi criado, em 1999, o Fundo de Aval para a Geração de Emprego e Renda (Funproger), que procurou compartilhar com as instituições financeiras o risco dos financiamentos.

O Proger Urbano, principal linha do programa, foi responsável, em 2006 , por $80 \%$ das operações de crédito. Essa linha está pautada na sustentabilidade dos empreendimentos financiados e na geração e manutenção de empregos e renda, contemplando linhas de crédito de apoio a micro e pequenos empreendedores, profissionais liberais, empreendedores populares, cooperativas e associações de produção. Os públicos-alvo do Proger são setores da atividade econômica, não havendo discriminação em termos de segmentos da população. Situação diferente se dá com o Programa Nacional de Fortalecimento da Agricultura Familiar (Pronaf), que possui uma linha de atuação voltada especificamente para mulheres agricultoras, integrantes de unidades familiares de produção, denominada Pronaf Investimento Mulher.

\section{Programa Nacional de Economia Solidária}

A Economia Solidária, também uma das novas funções incorporadas no SPETR, visa garantir o acesso dos "grupos vulneráveis" ao trabalho ou aos programas de geração de emprego e renda, dos quais as formas solidárias de organização produtiva são elementos constituintes. Ela compreende o conjunto de atividades econômicas - de produção, distribuição, consumo e crédito - organizadas e realizadas solidariamente, sob forma coletiva e autogestionária, e constitui uma resposta dos(as) trabalhadores(as) e das comunidades pobres às transformações do mundo do trabalho.

Esse programa tem se expandido a partir de instituições que apoiam iniciativas associativas comunitárias e pela constituição e articulação de cooperativas populares, redes de produção e comercialização, feiras de cooperativismo etc., e vem recebendo crescente apoio de governos municipais e estaduais. Vários são os programas públicos de Economia Solidária: bancos do povo, empreendedorismo popular soli- 
dário, incubação, centros populares de comercialização, entre outros. Em âmbito nacional, o governo federal criou, em 2003, a Secretaria Nacional de Economia Solidária (Senaes), cuja finalidade é promover o fortalecimento e a divulgação da Economia Solidária, visando ao desenvolvimento, mediante políticas integradas de geração de trabalho e renda, com inclusão social.

Vale destacar, porém, a ausência da incorporação da dimensão de gênero e raça/etnia no âmbito do programa. Embora os dados disponíveis no Sistema de Informação em Economia Solidária (Sies) ${ }^{10}$, desenvolvido pela Senaes, não permitam conclusões a respeito da inclusão da população segundo a raça/cor, os dados de gênero indicam uma situação bastante desfavorável para as mulheres nos empreendimentos solidários.

Com efeito, é possível perceber, pelo levantamento realizado em 2007, que a segregação das mulheres nos setores tradicionalmente identificados com o trabalho doméstico, observada no mercado de trabalho em geral, se repete nas experiências de Economia Solidária: quando se consideram os setores de costura, alimentação, reciclagem, calçados, fábricas recuperadas e empreendimentos de profissionais qualificados, observa-se, primeiramente, que elas predominam nos setores de costura e alimentação, e são maioria, ainda que convivendo com uma maior presença masculina, na reciclagem e no setor de calçados. Os homens predominam nas fábricas recuperadas e nos empreendimentos de profissionais qualificados ${ }^{11}$.

Em segundo lugar, observa-se que a precariedade das formas de organização dos empreendimentos dos setores de costura, calçados, alimentação e reciclagem se manifesta na predominância dos grupos informais como forma de organização, nas dimensões reduzidas dos empreendimentos (maior porcentagem de empreendimentos na faixa de 1 a 10 sócios) e no tipo de infraestrutura, a saber, em instalações provisórias com ocupação de locais cedidos por terceiros. Nas empresas recuperadas e entre os empreendimentos de profissionais qualificados, há maior tendência de organização em cooperativas, portanto, de maior formalização e um número maior de associados, sendo que, nas primeiras, predominam as que contam com mais de 21 associados.

Em terceiro lugar, os rendimentos auferidos pelos(as) sócios(as) dos setores de costura, calçados, alimentação e reciclagem, na maioria dos casos, são inferiores ao salário mínimo, o que é agravado pelo fato 
de eles(as) não terem acesso aos benefícios assegurados pela Consolidação das Leis do Trabalho (CLT). Vale destacar a predominância feminina nos setores nos quais os rendimentos são muito baixos ou inexistentes. Essas constatações indicam as dificuldades para que as trabalhadoras e os trabalhadores se fixem nesses empreendimentos, o que ocasiona instabilidade e pouca probabilidade de consolidação e de sobrevivência a longo prazo. Cabe ressaltar que, nesse contexto, as empresas recuperadas e os empreendimentos dos profissionais qualificados estão em melhor situação seja quanto ao patamar da remuneração de seus associados (em cerca de $20 \%$ desses empreendimentos, os rendimentos são maiores do que dois salários mínimos), seja quanto ao acesso a certos direitos trabalhistas, parecendo indicar maior consolidação, bem como melhor adaptação dessas organizações às condições de mercado.

Finalmente, no que concerne aos benefícios decorrentes do apoio do poder público, de entidades sindicais e não governamentais (ONGs) que poderiam minimizar os problemas anteriormente assinalados, cabe observar que, se de um lado esse apoio está presente e pode ter sido decisivo na formação de parte significativa desses empreendimentos, de outro ele parece não ser suficiente para melhorar as condições de vida dos associados e garantir condições de expansão e sobrevivência dos empreendimentos ${ }^{12}$.

\section{OS PLANOS PLURIANUAIS (PPAS) E O ENFRENTAMENTO DAS DESIGUALDADES SOCIAIS}

Instituídos pela Constituição de 1988, os PPAs são um instrumento de planejamento que constitui a base para a elaboração da proposta de orçamento nacional enviada anualmente pelo presidente da República, por meio do Ministério do Planejamento, Orçamento e Gestão (MPOG), ao Congresso Nacional.

No PPA correspondente ao período de 2000 a 2003, o tema da igualdade de gênero e raça aparecia de forma muito indireta: promover os direitos das minorias vítimas de preconceito e discriminação. Havia apenas dois programas dirigidos a mulheres (na área de combate à violência), e as ações relativas às mulheres e às populações negras e indígenas eram muito limitadas.

A partir de 2003, o governo transforma a redução das desigualdades sociais e a inclusão social em estratégias de longo prazo. Elas estão in- 
seridas no primeiro "megaobjetivo" da política de desenvolvimento a ser levada a efeito no período de 2004 a 2007, cujos objetivos são: "promover o acesso universal, com qualidade e equidade à seguridade social (saúde, previdência e assistência); promover a redução das desigualdades de gênero [e de raça]" (Brasil. MPOG, 2004b:56); entre outros.

O compromisso com a promoção da igualdade de oportunidades no mercado de trabalho e nas demais esferas da vida social, expresso no PPA 2004-2007, segue adiante no PPA 2008-2011, que tem como um de seus principais objetivos a "transversalização" de gênero e raça no conjunto das políticas elaboradas pelo governo federal.

Convém sublinhar a importância e o ineditismo da inclusão do compromisso com a transversalidade de gênero e raça nos PPAs, a qual permitiu não só estabelecer novas diretrizes para as políticas do MTE, mas, sobretudo, tornar as questões de gênero e raça uma constante no planejamento do governo (Abramo, 2007:248). É em função dessa evolução que se pode entender a criação da SPM e da Seppir. A partir de então, o governo se propõe a pautar suas ações pela ideia do Estado "como condutor do desenvolvimento social e regional e como indutor do crescimento econômico" (Brasil. MPOG, 2004b:15), fazendo "da justiça social a nova alavanca do desenvolvimento" (id., 2004a). Tal posicionamento é de grande importância para a questão da igualdade de oportunidade de gênero e raça.

\section{PPA 2004-2007}

O PPA 2004-2007, intitulado "Plano Brasil de Todos: Participação e Inclusão", afirma que o governo tem como principal desafio "[...] eliminar a fome e a miséria que envergonham a Nação" [...] (Brasil. MPOG, 2004b:13).

Para fazer frente a esse desafio, o plano propõe-se a inaugurar a seguinte estratégia de longo prazo:

inclusão social e desconcentração de renda com vigoroso crescimento do produto e do emprego; crescimento ambientalmente sustentável, redutor das disparidades regionais, dinamizado pelo mercado de consumo de massa, por investimentos e por elevação da produtividade; redução da vulnerabilidade externa por meio da expansão das atividades 
competitivas que viabilizam o crescimento sustentado; e fortalecimento da cidadania e da democracia (id., ibid.:15).

Essa estratégia questiona a elevação da produtividade resultante dos processos anteriores de ajuste da economia por não terem resultado em melhorias aos rendimentos do trabalhador, permanecendo restrita a uma pequena parcela da força de trabalho. Segundo o documento, isso só será revertido com o comprometimento do governo com as políticas sociais, ou seja, se houver "políticas de emprego, de inclusão social e de redistribuição de renda" (ibid.:18).

O PPA 2004-2007 toma as políticas sociais e de emprego como um fator de fortalecimento do consumo popular, entendendo que "o modelo só poderá adquirir impulso definitivo por meio do efeito do crescimento sobre o mercado de trabalho", sendo necessário que a demanda por mão de obra seja superior à expansão da oferta de trabalho (ibid.:19).

A geração de emprego e renda, segundo o megaobjetivo II do plano, objetiva

alcançar o equilíbrio macroeconômico com a recuperação e sustentação do crescimento e distribuição de renda, geração de trabalho e emprego; ampliar as fontes de financiamento internas e democratizar o acesso ao crédito para o investimento, a produção e o consumo; ampliar a oferta de postos de trabalho, promover a formação profissional e regular o mercado de trabalho, com ênfase na redução da informalidade (ibid.:57).

Na base dessas propostas, está a constatação de que

[...] a pobreza, a desigualdade e o desemprego, associados às precárias condições de alimentação, saúde, educação e moradia, concorrem para a marginalização de expressivos segmentos sociais, que não têm acesso a bens essenciais e que se encontram alijados do mundo do trabalho, do espaço público e das instituições relacionadas. Enfrentar este quadro é o principal desafio do Estado brasileiro expresso nesse Plano. Trata-se de ampliar a cidadania, isto é, atuar de modo articulado e integrado, de forma a garantir a universalização dos direitos sociais básicos e, simultaneamente, atender às demandas diferenciadas dos grupos socialmente mais vulneráveis da população (ibid.:61).

No que respeita às desigualdades raciais, o documento afirma que é no governo que se originam as políticas de erradicação da discriminação. 
Elas pressupõem o "fortalecimento de espaços de diálogo e parcerias com a sociedade civil organizada" (ibid.:90). Cabe ao programa Gestão da Política de Promoção da Igualdade Racial, quanto às políticas afirmativas, administrar a relação entre o governo e a sociedade civil organizada. Isso inclui "campanhas de conscientização, concessão de bolsas para estudantes negros e apoio a iniciativas de promoção da igualdade racial" (ibid.).

O projeto do governo em relação às desigualdades de gênero tem como prioridade a "transversalização" em toda política formulada no âmbito governamental, englobando horizontal e verticalmente todas as instâncias de poder da administração federal. Quanto à igualdade de oportunidades no mercado de trabalho, o programa Igualdade de Gênero nas Relações de Trabalho busca "contribuir para a promoção da equidade, com vistas a garantir a inclusão das mulheres no trabalho, $\mathrm{o}$ acesso e permanência em postos compatíveis com sua habilidade profissional, investindo especialmente na elevação da escolaridade e no aperfeiçoamento das capacidades técnica e gestora" (ibid.:92).

Há que se assinalar, contudo, que, embora importantes, essas iniciativas não são suficientes para mudar a situação da mulher no mercado de trabalho, na medida em que não interferem nas estruturas que lhe atribuem a responsabilidade exclusiva do cuidado da família e dos filhos. Para que isso seja alterado, outros "serviços" e "equipamentos" devem ser criados a fim de liberar a mão de obra feminina da dupla jornada e da sobrecarga de trabalho. Esses serviços e equipamentos externos ao espaço doméstico são as creches, as lavanderias e os restaurantes. Trata-se também de chamar a atenção para o papel desempenhado pelos homens no âmbito doméstico, que precisa ser questionado e desconstruído, a fim de responsabilizá-los, do mesmo modo que as mulheres, pelo cuidado da família e dos filhos. Essa última questão não está, todavia, colocada no PPA 2004-2007, embora esteja contemplada a criação de serviços que visam reduzir os encargos decorrentes do trabalho doméstico sobre as mulheres, como a ampliação do número de creches.

Num balanço do PPA 2004-2007, no que tange à igualdade de gênero e raça, Laís Abramo (2007) ressalta duas novidades: a primeira consiste na introdução do recorte transversal de gênero e raça; a segunda diz respeito ao fato de ter havido uma participação importante da sociedade civil em sua elaboração. Essa segunda novidade introduziu três no- 
ções importantes para a política pública: 1) a de que, mais que políticas específicas para as mulheres, o PPA deveria evoluir em direção a um enfoque de gênero para as políticas públicas; 2 ) a necessidade de criação de indicadores claros, tanto de processo quanto de impacto; 3 ) a exigência de uma capacitação sistemática dos servidores públicos nos temas de gênero e raça, com a devida alocação dos recursos necessários à viabilização desse processo (ibid.:249-250).

De acordo com a autora, a existência de dois programas voltados especificamente para o tema da transversalização de gênero e raça, respectivamente na SPM e na Seppir, indica não só mais compromisso com a igualdade de gênero e raça em relação aos governos anteriores como também colabora para ampliar a visibilidade desses temas enquanto objetivos de governo. Contraditoriamente, porém, a falta de indicadores específicos de gênero nos diversos programas executados pelos ministérios constitui um problema sério, na medida em que dificulta a avaliação dos resultados, das limitações e das dificuldades enfrentadas.

\section{PPA 2008-2011}

O PPA 2008-2011 - "Desenvolvimento com Inclusão Social e Educação de Qualidade" - está estruturado em torno de três eixos: crescimento econômico, agenda social e educação de qualidade. O eixo Agenda Social é o que dá continuidade às ações voltadas para as parcelas da população mais vulneráveis econômica e socialmente, com ênfase "nas transferências condicionadas de renda associadas às ações complementares; no fortalecimento da cidadania e dos direitos humanos; na cultura e na segurança pública" (Brasil. MPOG, 2007:13). Nele, o governo reitera o compromisso assumido de combater o preconceito e a discriminação.

Esse plano possui dois objetivos que se articulam com a igualdade de gênero, raça e etnia, e a redução das desigualdades no trabalho: “1) promover a inclusão social e a redução das desigualdades; 2) promover o crescimento econômico ambientalmente sustentável, com geração de empregos e distribuição de renda" (id., ibid.:46).

O cumprimento do primeiro objetivo deve se efetivar por meio da "consolidação de ações dirigidas à conquista de direitos básicos de cidadania pela população mais vulnerável e excluída socialmente" (ibid.: 64), o que significa "a continuidade da queda dos indicadores de 
pobreza e desigualdade por meio do aumento da renda e do consumo das famílias mais pobres" (ibid.:68). O documento esclarece que os programas de transferência de renda não são suficientes para garantir a realização desse objetivo, pois devem contemplar ações complementares de educação, qualificação profissional e de geração de trabalho e renda (ibid.).

No campo da geração de trabalho e renda, mantêm-se os segmentos "mais vulneráveis" como prioridade, ou seja, "mulheres chefes de família, afro e índio-descendentes, desempregados de longa duração, pessoas portadoras de necessidades especiais, etc." (ibid.:69).

Ainda que o PPA 2008-2011 celebre as conquistas do PPA anterior, ele nos lembra que os desafios ainda são muitos e que o atual período de governo não deve perder de vista que

a continuidade do modelo que conjuga crescimento econômico com inclusão social e redução das desigualdades passa pela consolidação e articulação das políticas sociais, que deverão atuar de forma cada vez mais integrada, promovendo, em conjunto com o crescimento econômico, a geração de empregos e a melhoria das condições de vida da população, especialmente "as mais vulneráveis", no que concerne a questões como educação, saúde, trabalho, renda, alimentação e nutrição, habitação, cultura, respeito à diversidade e outros (ibid.:71).

O governo identifica que muito se avançou em relação ao combate às desigualdades de gênero. Entretanto, ainda persiste "a hierarquização de sexo", o que determina às mulheres "espaços menos valorizados" (ibid.:82). O programa Pró-Equidade de Gênero, implementado pela SPM, está voltado precisamente para a correção dessas distorções - às empresas que adotam o programa e implementam suas diretrizes é conferido um distintivo. Em 2006, foi editada a lei 11.324, voltada para os trabalhadores e para as trabalhadoras domésticas, e que permite a dedução, no Imposto de Renda, da contribuição feita à Seguridade Social, visando estimular a "formalização" do trabalho doméstico, exercido, sobretudo, por mulheres.

O PPA considera que, tal como as desigualdades de gênero, as de raça estão presentes em todas as esferas da vida social e implicam, na verdade, maior grau de restrição de cidadania do que as de gênero/sexo. Os negros apresentam indicadores piores, tanto em termos de educação quanto de trabalho. Contudo, é no mercado de trabalho que as desigualdades étnico-raciais, assim como as de gênero, se expressam mais fortemente. 
As ações governamentais de combate à discriminação étnico-racial estão pautadas pela "criminalização do racismo", pela "proibição da discriminação no trabalho, na educação, na liberdade de crença, no exercício dos direitos culturais ou de qualquer outro direito ou garantia fundamental" e pela "ação afirmativa"13. Esta última chama a atenção para a "responsabilidade do Estado de esforçar-se na criação de condições que permitam a todos se beneficiarem da igualdade de oportunidades" (Brasil. Seppir, 2003:5).

Todavia, também no II PPA a incorporação da perspectiva de gênero e raça no combate às desigualdades sociais e à exclusão mantém-se incipiente e insuficiente. Tal insuficiência se expressa tanto na inexistência de indicadores de mensuração e de avaliação dos resultados dos programas que incorporam essa perspectiva (já apontada nos comentários ao I PPA) quanto na limitação da dotação orçamentária aos programas dirigidos às mulheres e aos negros com dimensão de gênero e raça, embora tanto a SPM quanto a Seppir apontem, em seus relatórios, um pequeno aumento na dotação orçamentária desde 2003.

\section{SPM E SEPPIR: O RECONHECIMENTO DAS DESIGUALDADES DE GÊNERO E RAÇA COMO PROBLEMAS ESPECÍFICOS E COMO ENTRAVES À CONSOLIDAÇÃO DA DEMOCRACIA}

A Secretaria Especial de Políticas para as Mulheres (SPM), criada em 1은 de janeiro de 2003, consiste numa importante inovação institucional. Nascida com a função especial de promover a transversalização de gênero nas várias esferas do governo, ela foi seguida, em meio a uma forte pressão do movimento social, pela criação da Secretaria Especial de Políticas de Promoção da Igualdade Racial (Seppir), em 21 de março de 2003, voltada para a transversalização de raça nas diferentes esferas governamentais. Ambas estão ligadas diretamente à Presidência e seus dirigentes possuem status de ministro, ainda que seus órgãos não constituam propriamente ministérios. Propondo-se a saldar uma dívida histórica com a desigualdade social, essas secretarias se configuram como as mais importantes inovações institucionais voltadas para a promoção da igualdade de gênero e raça no país.

\section{Secretaria Especial de Políticas para as Mulheres (SPM)}

ASPM orienta sua política nacional pelos seguintes princípios: "igualdade e respeito à diversidade; equidade; autonomia das mulheres; laicidade do Estado; universalidade das políticas; justiça social; transpa- 
rência dos atos públicos; e participação e controle social" (PNPM, 2005), os quais têm origem na I Conferência Nacional de Políticas para as Mulheres, realizada em 2004, na qual foram também lançadas as bases para a construção do Plano Nacional de Políticas para as Mulheres (PNPM). Este, por sua vez, põe no centro da discussão o papel do Estado como "promotor e articulador de ações políticas" que alterem o quadro de desigualdades existente no país. Seu objetivo consiste em consolidar um estado de direito, em que as ações voltadas para o combate das desigualdades se tornem permanentes.

O PNPM possui uma linha de atuação (autonomia, igualdade no mundo do trabalho e cidadania) voltada mais diretamente para a incorporação da dimensão de gênero nas políticas de emprego, trabalho e renda. Essa linha comporta objetivos, metas, prioridades e ações relacionadas ao mundo do trabalho e aos direitos das mulheres à documentação, à propriedade, à infraestrutura urbana e rural e à habitação (Brasil. SPM, 2006:25).

Os objetivos pressupõem a promoção da autonomia econômica e financeira das mulheres; da equidade de gênero, raça e etnia nas relações de trabalho; de políticas de ações afirmativas que reafirmem a condição das mulheres como sujeitos sociais e políticos; da ampliação da inclusão das mulheres na reforma agrária e na agricultura familiar; do direito à vida na cidade com qualidade e acesso a bens e a serviços públicos.

As principais metas são: adotar medidas que promovam a elevação, em 5,2\%, na taxa de atividade das mulheres entre 2003 e 2007; manter a média nacional de no mínimo $50 \%$ de participação das mulheres no total de trabalhadores atendidos pelo PNQ; conceder crédito a 400 mil mulheres trabalhadoras rurais no período de 2005 a 2006; documentar 250 mil mulheres rurais no período de 2004 a 2007. Além disso, há outra meta importante para o tema do trabalho, que consiste em aumentar em $12 \%$, entre 2004 e 2007, o número de crianças entre 0 e 6 anos de idade frequentando creche ou pré-escola, a qual, embora relacionada a outra linha do PNPM (educação inclusiva e não sexista), tem um impacto importante no trabalho das mulheres com filhos pequenos.

Dentre as prioridades e suas respectivas ações vale destacar: a ampliação do acesso das mulheres ao mercado de trabalho, composta de ações dirigidas, sobretudo, ao atendimento prioritário das mulheres nas políticas ativas de mercado de trabalho (intermediação e qualificação de 
mão de obra, qualificação de jovens) e nas ações de fiscalização do trabalho. A SPM também contempla uma ação voltada especificamente para a capacitação de mulheres quilombolas, visando à geração de emprego e renda, e o apoio aos estados e municípios na construção de equipamentos sociais para facilitar a inserção e a permanência das mulheres no mercado de trabalho (creches, restaurantes e lavanderias públicas).

Conforme aponta Abramo (2007), estas últimas são as únicas ações do conjunto do PNPM que têm relação com o tema da conciliação entre o trabalho e outros âmbitos da vida das mulheres, especialmente no que se refere às suas responsabilidades domésticas e familiares. Outra prioridade importante consiste na promoção da autonomia econômica e financeira das mulheres a partir do apoio ao empreendedorismo, associativismo, cooperativismo e comércio. Ela é composta de ações voltadas notadamente para os apoios técnico e financeiro (concessão de crédito) a projetos de geração de trabalho e renda, como cooperativas, associações e empreendimentos baseados nos princípios da economia solidária, com foco nas famílias chefiadas por mulheres.

Também vale ressaltar a prioridade conferida à garantia do cumprimento da legislação no âmbito do trabalho doméstico e o estímulo à divisão das tarefas domésticas, a qual reúne ações focadas, principalmente, na ampliação dos direitos e na melhoria das condições de trabalho das trabalhadoras domésticas, incluindo campanhas contra o trabalho infantil doméstico.

Finalmente, a prioridade dada à ampliação do exercício da cidadania das mulheres e de seu acesso à terra e à moradia envolve ações centradas nos temas: fortalecimento e implementação do programa de Documentação da Mulher Trabalhadora Rural e da titulação conjunta da terra nos programas de Reforma Agrária; apoio a programas de urbanização de favelas, com especial atenção às mulheres chefes de família; incentivo a ações integradas entre o governo federal, governos estaduais e municipais para promoção do saneamento básico e acesso à água, visando assegurar moradia em ambientes saudáveis e estímulo à eletrificação das comunidades rurais, dando prioridade a serviços e equipamentos que incidam diretamente na vida das mulheres.

Resumindo esse conjunto de objetivos, metas e ações, é possível verificar que ele está voltado tanto para o emprego formal e assalariado (igualdade salarial, acesso a cargos de direção no serviço público, ne- 
gociação coletiva) quanto para o informal (acesso a recursos produtivos como crédito e terra, acesso à assistência técnica, estímulo ao associativismo, cooperativismo e a outras formas de economia solidária), coincidindo com as resoluções tomadas pelo II Congresso do SPETR.

Como destaca Abramo, essa linha de atuação do PNPM inclui “[...] as únicas ações do plano referidas à infraestrutura urbana e rural e de serviços: acesso à água potável, ao saneamento básico, à eletrificação e à habitação, dentro da lógica de liberar o tempo das mulheres para as atividades produtivas e o trabalho remunerado" (ibid.:258).

Por sua vez, como lembra a autora, o tema das creches não aparece nessa linha de atuação, mas na que se refere à educação não sexista e inclusiva, não havendo,

[...] no conjunto do plano, nenhuma outra meta, objetivo, prioridade ou ação que atenda à questão da conciliação entre o trabalho extradoméstico e a vida familiar e da promoção de um melhor equilíbrio entre homens e mulheres em relação às responsabilidades domésticas e familiares. Essa ausência reflete, sem dúvida, uma debilidade desse conjunto de iniciativas e propostas, já que não trata de uma dimensão central para a promoção da igualdade de gênero no mundo do trabalho (ibid.).

Por fim, valeria comentar a definição da meta mais geral da linha, discutida por Abramo (2007), relativa à elevação da taxa de atividade. O problema que aí se coloca está no fato de a meta não ter sido definida em relação à taxa de ocupação ou de emprego, na medida em que não tem muito sentido aumentar a taxa de atividade das mulheres se isso não significar uma elevação de sua taxa de ocupação ou de emprego.

No que respeita às demais metas da linha de autonomia no trabalho, segundo o Sistema de Acompanhamento do PNPM, o atendimento às mulheres cumpriu a meta na maior parte dos programas. No PNQ, elas corresponderam a $56 \%$ do total dos trabalhadores qualificados em 2005 e a 58\% em 2006; no programa de Primeiro Emprego, dos 18.355 jovens atendidos, 53,4\% eram mulheres em 2005, proporção mantida no ano seguinte; no que diz respeito à intermediação de mão de obra, em 2006 foram recolocadas, por meio do Sine, 212.476 mulheres, o que corresponde a $53,4 \%$ do total de trabalhadores recolocados.

Nos balanços de ações, é recorrente a citação dos participantes / parceiros em cada uma das ações desenvolvidas. É importante ressaltar que a atuação da SPM, assim como da Seppir, não se efetiva isoladamente, 
mas de forma conjunta, com a participação de outros ministérios e secretarias do governo, das demais esferas de governo - estados e municípios - e de outros atores sociais, como a sociedade civil organizada. Para que isso fosse possível, tratou-se, em alguns casos, de reformular a institucionalidade existente, dando-lhe novos contornos - como é o caso do Conselho Nacional dos Direitos da Mulher, que integrava o Ministério da Justiça e, a partir da criação da SPM, passou a integrar sua estrutura. Em outros casos, tratou-se de constituir uma secretaria inteiramente nova - um exemplo é a própria criação da SPM, assim como da Seppir. Esses fatos necessitam ser destacados em função de sua importância no sentido de criar uma institucionalidade voltada, precipuamente, para as ações de promoção da igualdade de gênero e raça.

Se esse conjunto de ações e de novas institucionalidades significa um avanço considerável, na medida em que expressa o fato de que o combate às desigualdades de gênero e raça aparece pela primeira vez na história do país como um objetivo importante do plano estratégico de governo, isso não significa, como demonstra Abramo (ibid.:267), que esse planejamento estratégico tenha sido feito com uma perspectiva de gênero: o número de programas é reduzido, assim como sua dotação orçamentária, além de que poucos ministérios contam com estruturas de gênero e programas próprios e bem localizados nas respectivas estruturas de poder, além do fato, já sublinhado, de que as políticas carecem de indicadores capazes de permitir um acompanhamento adequado dos resultados dos programas e ações, dificultando a efetivação da transversalização.

No entanto, a importância do PNPM não deve ser desprezada. Por um lado, pela centralidade que as questões de gênero vêm assumindo nas discussões sobre políticas de combate às desigualdades sociais e, mais que isso, pelo retorno do Estado como indutor da dinâmica de redução dessas desigualdades. Por outro, em virtude de seu propósito de integrar as ações de vários ministérios em relação a objetivos definidos num processo de ampla participação e discussão, como foi a I Conferência Nacional de Políticas para as Mulheres. Da mesma forma, como ressalta Abramo,

[...] ainda que as metas, ações e objetivos definidos no PNPM tenham deixado de abarcar algumas áreas importantes para a política de promoção da igualdade de gênero (como, por exemplo, os temas relativos à conciliação entre a vida e o trabalho), o fato de ter sido possível avan- 
çar no cumprimento das metas definidas também pode ser visto como um passo importante de um processo cumulativo (ibid.).

\section{Secretaria Especial de Políticas de Promoção da Igualdade Racial (Seppir)}

A Seppir foi criada com o objetivo de "coordenar políticas no campo da proteção aos direitos de indivíduos e grupos raciais e étnicos afetados por discriminação - negros, indígenas, ciganos, árabes, palestinos, judeus e outros, bem como pelas diversas formas de intolerância" (Brasil. Seppir, 2006a).

Essa secretaria possui seis programas principais: implementação de um modelo de gestão da política de promoção da igualdade racial; apoio às comunidades remanescentes de quilombos; ações afirmativas; desenvolvimento e inclusão social; relações internacionais; e produção do conhecimento. Tais programas foram desenhados e implementados por meio da Política Nacional de Promoção da Igualdade Racial (PNPIR).

A PNPIR tem por objetivo orientar o conjunto das ações do governo federal em relação às desigualdades raciais, visando, centralmente, à redução das "desigualdades raciais no Brasil, com ênfase na população negra" (Brasil. Seppir, 2003:7).

A questão racial é considerada "um desafio ao ideário democrático" e "um entrave para a consolidação da democracia e do desenvolvimento econômico do país" (id., ibid.:Introdução). Para que essa política seja viabilizada, propõe-se que todos os atores comprometidos com a justiça social no Brasil concentrem esforços no sentido de erradicar toda e qualquer forma de discriminação.

Quanto às diretrizes propostas na área de trabalho, emprego e renda, a política propõe um amplo conjunto de medidas, dirigidas especialmente a: efetivar a implementação das convenções 100, 111 e 169 da OIT, concernentes à discriminação em matéria de emprego, salário e profissão; implementar, no serviço público, o programa de combate ao racismo institucional; implementar a dimensão de raça, gênero e juventude nas políticas públicas de trabalho, renda e empreendedorismo, formação profissional, programas de emprego de emergência e microcrédito; criar mecanismos de fiscalização quanto à prática de discriminação racial na ocupação de vagas no mercado de trabalho; estru- 
turar um sistema de indicadores de raça e gênero para avaliação e monitoramento das políticas públicas de geração de emprego e renda, e combate à discriminação racial e à pobreza; assegurar a introdução do quesito raça/cor nos formulários públicos de morbidade e mortalidade no trabalho, bem como nos formulários de acidente de trabalho e das doenças ocupacionais, e incentivar que as empresas o façam.

Os instrumentos propostos para a implementação dessas diretrizes são as políticas especiais sob forma de ações afirmativas, entre as quais vale ressaltar: incluir as populações negras, indígenas, ciganas e remanescentes quilombolas em programas de capacitação e permanência no emprego; incentivar o comprometimento de empresas com a igualdade de oportunidades e de tratamento, mediante processos seletivos transparentes que explicitem os requisitos e as qualificações exigidas para o preenchimento de cargo ou função vacante; promover um amplo processo de sensibilização, capacitação e formação de gestores(as) públicos(as) especializados(as) nos temas de raça e gênero, e incentivar que estados e municípios o façam; promover políticas de formação e qualificação profissional para as populações desfavorecidas economicamente, em especial para pessoas de raça/etnia negra; realizar campanha nacional para estimular a geração de renda e o emprego para mulheres negras; garantir a política de ações afirmativas para as mulheres em todas as esferas do mercado de trabalho; defender a igualdade salarial e o estímulo à ascensão profissional das mulheres negras em todas as instâncias do mercado de trabalho; utilizar os recursos do FAT na qualificação profissional da mulher negra; promover o fortalecimento da capacidade gerencial, técnica e profissional das mulheres negras, indígenas e quilombolas, visando à redução paulatina do peso do emprego doméstico na população ocupada desse contingente.

Destaque-se também que a PNPIR prevê a estruturação de um sistema de indicadores de raça e gênero para avaliação e monitoramento das políticas públicas, assim como o incentivo à realização de pesquisas no campo do trabalho, emprego e renda, e a criação de um banco de dados a ser disponibilizado para a sociedade.

Em relação à área dos direitos humanos relativos ao trabalho, a PNPIR propõe: ampliar as ações de combate ao trabalho escravo em todo o território nacional, expropriando as terras de quem pratica esse crime; intensificar o programa de erradicação do trabalho infantil; estimular a 
Fundacentro a apresentar projeto de prevenção a acidentes e doenças de trabalho para negros, negras, índios e índias.

A avaliação da PNPIR exige que se considere, antes de tudo, que qualquer dispositivo antidiscriminatório pode influenciar a dinâmica do mercado de trabalho, especialmente se estiver inserido numa política de governo, como é o caso da PNPIR. Dentre os objetivos da política passíveis de promover essa influência, merecem destaque: a defesa de direitos, a ação afirmativa e a transversalidade.

No caso da defesa de direitos, trata-se de fazer cumprir os preceitos antidiscriminatórios da Constituição de 1988, que "criminalizou" o racismo, a fim de coibir a "discriminação no trabalho, na educação, na liberdade de crença, no exercício dos direitos culturais ou de qualquer outro direito ou garantia fundamental" (Brasil. Seppir, 2003:8; ênfase nossa).

A ação afirmativa é o instrumento privilegiado na formulação e na execução de projetos que garantam "o acesso e a permanência de grupos discriminados, nas mais diversas áreas - educação, saúde, mercado de trabalho, geração de renda, direitos humanos etc." (id., ibid.; ênfase nossa).

A transversalidade, por sua vez, permite que a questão racial permeie toda e qualquer política pública, desde sua formulação até sua execução. No Relatório de Avaliação 2003-2006, a transversalidade aparece em duas ações principais: "na incorporação dos valores de equidade étnico-racial às iniciativas do Estado, por meio da inserção de ações de igualdade racial em todas as áreas da política pública", e "na capacitação dos gestores nos temas transversais" (Brasil. Seppir, 2006b:21).

Na primeira ação, situam-se o programa Brasil Quilombola e a Ouvidoria e Monitoramento de Leis, que tratam das práticas de racismo e de discriminação racial junto aos órgãos governamentais. Segundo o relatório, de 2005 para 2006, houve um aumento no número de denúncias e de reclamações, que passaram, respectivamente, de 55 para 314. Dentre os itens apurados cabe destacar o crescimento quanto à discriminação racial no ambiente de trabalho. Embora o relatório não explicite o porquê desse aumento, é possível que esteja relacionado à publicização da questão racial e à criação de canais de participação e espaços institucionais para o encaminhamento de denúncias e de reclamações. Isso permite expressar a indignação com relação a tais práticas e conferir-lhes o estatuto jurídico de "crime". 
Na segunda ação - capacitação dos gestores nos temas transversais -, o relatório aponta o diálogo que se estabeleceu com o Ministério Público "quando a Seppir promoveu a realização de oficinas sobre a transversalidade de gênero e raça nas ações do governo federal, com a participação de outros órgãos da administração" (id., ibid.:25). A ação, que passou a constar dos respectivos orçamentos de alguns dos órgãos que participaram da atividade, teve "o intuito de propiciar a formação nos temas de direitos humanos, gênero e raça de servidores públicos federais, estaduais e municipais, titulares de cargos políticos e agentes de segurança pública" (ibid.).

A transversalidade de gênero e raça nas políticas públicas é, conforme apontado anteriormente, um compromisso assumido pelo governo federal desde o I PPA 2004-2007; assim sendo, não se trata de tarefa exclusiva da Seppir, embora a secretaria, por meio da PNPIR, oriente as ações de todos os órgãos da administração pública federal em relação à questão racial.

Em 2004, por exemplo, o MTE realizou um seminário voltado especificamente para a transversalização das questões de gênero, raça e etnia no PNQ. Tratava-se de capacitar coordenadores estaduais e municipais do Plano Territorial de Qualificação (Planteq), uma das modalidades de execução do PNQ, visando à implementação de políticas públicas afirmativas de gênero, raça e etnia nos programas de qualificação social e profissional (Moraes, 2005).

A Seppir firmou um Termo de Cooperação Técnica com o MTE em 2003, que resultou na participação da secretaria nos seguintes programas e comissões:

Comissão Tripartite de Igualdade de Oportunidades de Gênero e Raça no Trabalho; Programa Primeiro Emprego; Programa de Qualificação e Requalificação Profissional; Programa Brasil, Gênero e Raça; e Plano Setorial de Qualificação de Trabalhadores Domésticos. Foi ainda constituído o Comitê da Diversidade, para agregar empresas, instituições governamentais e não governamentais com o intuito de criar oportunidades e promover a diversidade étnico-racial no mercado de trabalho (Brasil. Seppir, 2006b:87).

A secretaria também integrou "a Comissão Interministerial - coordenada pelo MTE - para o desenvolvimento da Agenda Nacional de Trabalho Decente" (id., ibid.). 
Apesar disso tudo, e do ineditismo em termos de políticas públicas que significa o Plano Nacional de Políticas para a Igualdade Racial, não se pode deixar de reconhecer que, assim como o Plano Nacional de Políticas para as Mulheres (PNPM), ele possui uma série de limitações, que vão desde sua reduzida dotação orçamentária à carência de estruturas voltadas especificamente para a promoção da igualdade racial e programas próprios e bem localizados nas respectivas estruturas de poder. Ademais, como já alertado anteriormente, as políticas carecem de indicadores capazes de permitir um acompanhamento adequado dos resultados dos programas implementados pelos diversos ministérios e secretarias especiais da Presidência da República. Nesse contexto, o objetivo da transversalização acaba não se efetivando, mesmo quando um conjunto de políticas de combate à desigualdade de gênero e raça é posto em prática por diferentes órgãos e instâncias do governo.

\section{CONSIDERAÇÕES FINAIS}

Buscamos demonstrar, nos tópicos anteriores, que o governo brasileiro abraçou, desde 2003, o desafio de implementar um modelo de desenvolvimento baseado na ideia de combate à desigualdade social, um fenômeno tão antigo quanto pouco enfrentado na história do país. Para tanto, especial atenção foi dada ao tema da desigualdade de gênero e raça no mercado de trabalho, dois dos pilares fundamentais da desigualdade social no Brasil.

A partir de então, o tema da igualdade de gênero e raça adquire destaque nas políticas governamentais, com a inserção da redução das desigualdades sociais e a inclusão social em estratégias de longo prazo.

Justamente nesse contexto, as políticas de promoção da igualdade de gênero e raça serão inseridas no primeiro "megaobjetivo" da política de desenvolvimento a ser levada a efeito no período de 2004 a 2007, fazendo-se presentes desde o I PPA, que já enfatizava a necessidade de erradicação das desigualdades raciais a partir de políticas públicas exercidas em parceria com a sociedade civil organizada, assim como o compromisso do governo em relação ao combate às desigualdades de gênero, além da remoção de obstáculos à inserção da mulher no mercado de trabalho, compromissos estes que seguem adiante e se consolidam no PPA 2008-2011.

Também cabe destacar a criação da Seppir e da SPM, visando à implementação de secretarias específicas, com o estatuto de ministérios, des- 
tinadas à formulação, coordenação e articulação de políticas de promoção da igualdade de gênero e raça de forma transversal ao conjunto de ministérios do governo e às demais áreas da administração pública. É em meio a essas políticas voltadas para as áreas em que a desigualdade se expressa que se situam as políticas públicas voltadas mais especificamente para a promoção da igualdade de oportunidades no mercado de trabalho.

Essas iniciativas, inéditas no país, constituem um importante esforço do governo federal no sentido de adotar medidas que possam se transformar em políticas de Estado, que garantam a estabilidade, a continuidade e a diversificação das ações de combate que, para serem efetivas, não podem estar articuladas às vontades dos governantes e sujeitas à barganha política.

Finalmente, valeria considerar que, se esse conjunto de esforços tem permitido um grande avanço no combate à discriminação de gênero e raça, ele ainda sofre de uma série de limitações, que se expressam, fundamentalmente, na dificuldade de transversalizar as políticas, seja nas diferentes ações do Sistema Público de Emprego, Trabalho e Renda, seja no interior de cada uma de suas funções, conforme ficou evidenciado, especialmente, pela análise do Sistema de Intermediação, Geração de Emprego e Renda e Economia Solidária, mas também do PNQ, da SPM e da Seppir.

Nesse sentido, até o momento, esses esforços não foram suficientes para erradicar as desigualdades de gênero e raça no mercado de trabalho, que ainda persistem, mesmo que de forma menos pronunciada.

(Recebido para publicação em abril de 2009)

(Versão definitiva em janeiro de 2010) 
Igualdade de Gênero e Raça no Brasil: Uma Discussão sobre a Política Pública...

\section{NOTAS}

1. A redefinição do papel do Ministério Público do Trabalho constituiu um avanço importante para a garantia dos direitos do trabalho no país. Conforme destacam Baltar, Krein e Leone (2009:45), "é possível perceber que alguns temas, considerados prioritários e colocados como metas institucionais, oferecem certa perspectiva mais nacional para a instituição, tais como: a erradicação do trabalho infantil; o combate ao trabalho forçado, às formas de discriminação, às cooperativas fraudulentas e à terceirização; a garantia dos direitos fundamentais do trabalho, especialmente a formalização; a inserção de pessoas portadoras de deficiência no mercado de trabalho; e a observância das normas de segurança e medicina do trabalho".

2. Uma excelente análise dos efeitos desse processo sobre a classe trabalhadora da Grande São Paulo, principal região metropolitana do país, pode ser encontrada em Kowarick e Brant (1976).

3. Não se pode esquecer, entretanto, que o FGTS consiste numa perda relativa em relação à legislação anterior, que previa a estabilidade do trabalhador no emprego depois de um período de dez anos de trabalho na mesma empresa. Ao criar o FGTS, o governo acabou com qualquer tipo de estabilidade, facilitando a demissão dos trabalhadores pelas empresas. Embora muitas delas adotassem a política de demitir o trabalhador às vésperas de ele cumprir os dez anos como forma de evitar a estabilidade, essa prática era difícil de ser aplicada em todos os casos, como nos dos trabalhadores mais qualificados, mais dedicados, mais produtivos etc.

4. O PIS é recolhido pelas empresas privadas; já o Pasep é uma contribuição das empresas públicas.

5. O Sine foi criado com o objetivo precípuo de fazer a intermediação da mão de obra.

6. OFAT foi criado com a finalidade de financiar o seguro-desemprego, o abono salarial e os programas de desenvolvimento econômico. Seus recursos provêm, sobretudo, das contribuições para o PIS e o Pasep. O fundo é administrado pelo Codefat, um órgão colegiado, de caráter tripartite e paritário, com representação do governo, empregadores e trabalhadores. Entre as funções mais importantes desse último órgão estão as de elaborar diretrizes para programas e para alocação de recursos, acompanhar e avaliar seu impacto social, e propor o aperfeiçoamento da legislação referente às políticas que lhe são correlatas. Igualmente importante é o papel que exerce no controle social da execução dessas políticas, no qual estão as competências de análise das contas do Fundo, dos relatórios executores dos programas, bem como de fiscalização e administração do FAT. Cf. Ministério do Trabalho e Emprego, Emprego e Renda, Fundo de Amparo ao Trabalhador. Disponível em http:/ /www.mte.gov.br. Acessado em abril de 2008.

7. Segundo Azeredo e Ramos (1995:94-95), “as políticas passivas têm como objetivo assistir financeiramente o trabalhador desempregado ou reduzir o excesso de oferta de trabalho. Seus instrumentos clássicos são: o seguro-desemprego e/ou indenização aos desligados, adiantamento da aposentadoria, redução da jornada de trabalho etc. Diferentemente, as políticas ativas visam exercer um efeito positivo sobre a demanda de trabalho. Os instrumentos clássicos desse tipo de política são: a criação de empregos públicos, a formação e a reciclagem profissional, a intermediação de mão de 
obra, a subvenção ao emprego e, em geral, as medidas que elevem a elasticidade emprego-produto".

8. Referimo-nos à visão assentada na divisão sexual do trabalho, que confere à mulher trabalhadora um papel secundário, pouco valorizado e subordinado no mercado de trabalho.

9. Esse avanço conceitual e metodológico se expressou especialmente na promoção de experiências denominadas, pelo Planfor, de inovadoras, que se dirigiam especificamente a mulheres.

10. OSies é um sistema de identificação e registro de informações dos empreendimentos econômicos solidários e das entidades de apoio, assessoria e fomento à economia solidária no Brasil. De acordo com a Portaria do MTE, n- 30, de 20 de março de 2006, ele compreende "o conjunto de atividades econômicas - de produção, distribuição, consumo, poupança e crédito - organizadas e realizadas solidariamente por trabalhadores e trabalhadoras sob a forma coletiva e autogestionária".

11. Esses setores estão sendo destacados por representarem os mais expressivos da Economia Solidária.

12. Cf. Araújo, Pontes e Lima (2009).

13. Ação afirmativa, ou ação positiva, "compreende um comportamento ativo do Estado em contraposição à atitude negativa, passiva e limitada à mera intenção de não discriminar" (Brasil. Seppir, 2003:8). 
Igualdade de Gênero e Raça no Brasil: Uma Discussão sobre a Política Pública...

\section{REFERÊNCIAS BIBLIOGRÁFICAS}

ABRAMO, Laís. (2007), A Inserção da Mulher no Mercado de Trabalho: Uma Força de Trabalho Secundária? Tese de doutorado em Sociologia, Faculdade de Filosofia, Letras e Ciências Humanas, Universidade de São Paulo, São Paulo.

e TODARO, Rosalba (comps.). (2002), Cuestionando un Mito: Costos Laborales de Hombres y Mujeres en América Latina. Lima, OIT/Oficina Regional para América Latina y el Caribe.

ARAÚJO, Angela, PONTES, Cecília e LIMA, Jacob Carlos. (2009), Empreendimentos Urbanos de Economia Solidária. Uma Análise Preliminar dos Dados da Base SIES. Material preparado para o II relatório do projeto de pesquisa A Crise do Trabalho e as Experiências de Geração de Emprego e Renda: As Distintas Faces do Trabalho Associado e a Questão de Gênero, coordenado por Marcia de Paula Leite, Angela Maria Carneiro Araújo e Jacob Carlos Lima. São Paulo, Fapesp.

AZEREDO, Beatriz. (1998), Políticas Públicas de Emprego: A Experiência Brasileira. São Paulo, Abet.

e RAMOS, Carlos Alberto. (1995), “Políticas Públicas de Emprego: Experiências e Desafios". Planejamento e Políticas Públicas, no 12. Rio de Janeiro, Ipea. Disponível em http://www.ipea.gov.br. Acessado em dezembro de 2007.

BALTAR, Paulo, KREIN, José Dari e LEONE, Eugênia Troncoso. (2009), "Economia e Mercado de Trabalho no Brasil", in M. de P. Leite e A. M. C. Araújo (orgs.), O Trabalho Reconfigurado. Ensaios sobre Brasil e México. São Paulo, Annablume.

BRASIL. MPOG (Ministério do Planejamento, Orçamento e Gestão). (2004a), "Mensagem do Presidente da República". Plano Plurianual 2004-2007. Brasília. Disponível em http:/ / www.planejamento.gov.br. Acessado em outubro de 2007.

. (2004b), Plano Plurianual 2004-2007. Brasília, MP. Disponível em http://www. planejamento.gov.br. Acessado em outubro de 2007.

. (2007), Plano Plurianual 2008-2011. Brasília, MP. (Caderno 1). Disponível em http://www.planejamento.gov.br. Acessado em outubro de 2007.

BRASIL. MTE (Ministério do Trabalho e Emprego). (1997), Política Pública de Emprego e Renda: Ações do Governo. Brasília, MTE.

__ (2003), Plano Nacional de Qualificação - PNQ 2003-2007. Brasília, MTE/SPPE.

. (2005), Trabalho Doméstico Cidadão. Brasília, MTE.

CODEFAT (Conselho Deliberativo do FAT) e FONSET (Fórum Nacional de Secretarias do Trabalho). (2005), II Congresso Nacional do Sistema Público de Emprego, Trabatho e Renda. São Paulo, MTE/Codefat/Fonset.

BRASIL. SEPPIR (Secretaria Especial de Políticas de Promoção da Igualdade Racial). (2003), Política Nacional de Promoção da Igualdade Racial. Brasília. Disponível em http:/ / www.brasil.gov.br. Acessado em novembro de 2007.

. (2006a), Informativo da Igualdade Racial - 2006. Brasília. Disponível em http:/ / www.brasil.gov.br. Acessado em novembro de 2007. 
. (2006b), Relatório de Avaliação 2003-2006. Brasília. Disponível em http:/ / www.brasil.gov.br. Acessado em novembro de 2007.

BRASIL. SPM (Secretaria Especial de Políticas para as Mulheres). (2006), Plano Nacional de Políticas para as Mulheres. Brasília. Disponível em http:/ / www.brasil.gov.br. Acessado em dezembro de 2007.

CARDOSO JR., José Celso et alii. (2006), "Políticas de Emprego, Trabalho e Renda no Brasil: Desafios à Montagem de um Sistema Público, Integrado e Participativo". Texto para Discussão no 1.237. Brasília, Ipea. Disponível em http:/ / www.ipea.gov.br. Acessado em outubro de 2007.

IE/CESIT / UNICAMP. (2005), O Sistema Público de Emprego no Brasil: Quadro Geral e Principais Desafios. II Congresso Nacional do Sistema Público de Emprego, Trabalho e Renda. São Paulo, MTE/Codefat/Fonset, 24-26 de agosto.

KOWARICK, Lúcio e BRANT, Vinícius Caldeira. (1976), São Paulo 1975: Crescimento e Pobreza. São Paulo, Edições Loyola.

LEITE, Marcia de Paula e SOUZA, Silvana Maria. (2002), "Costos del Trabajo Femenino: Imágenes y Realidades en el ABC Paulista", in L. Abramo e R. Todaro (comps.), Cuestionando un Mito: Costos Laborales de Hombres y Mujeres en América Latina. Lima, OIT/Oficina Regional para América Latina y el Caribe, cap. 5.

. (2005), Quadro Geral da Dimensão de Gênero e Raça no PNQ. Unicamp, Faculdade de Educação. Mimeo.

MORAES, Eunice Léa de. (2005), Relação Gênero e Raça na Política Pública de Qualificação Social e Profissional. Brasília, MTE/ SPPE/DEQ.

NABUCO, Maria Regina, CASTRO, Gilberto Ribeiro e DUTRA, Ricardo Rodrigues. (2005), Experiências Locais de Geração de Emprego e Renda no Brasil: A Experiência do Estado de Minas Gerais, 2000. II Congresso Nacional do Sistema Público de Emprego, Trabalho e Renda. São Paulo, MTE/Codefat/Fonset, 24-26 de agosto.

OIT (Organização Internacional do Trabalho). (2005), Manual de Formação e Informação do Programa de Fortalecimento Institucional para a Igualdade de Gênero e Raça, Erradicação da Pobreza e Geração de Emprego. Brasília, OIT.

PNPM (Plano Nacional de Políticas para as Mulheres). (2005), Plano Nacional de Políticas para as Mulheres. Brasília, SPM.

SARDENBERG, Cecília M. Bacellar e COSTA, Ana A. Alcântara. (2006), Desenvolvimento de Ações no Campo da Qualificação Social e Profissional para Promoção da Inclusão de Trabalhadores e Trabalhadoras, MTE-OIT. Documento de Trabalho, maio. 


\section{ABSTRACT \\ Gender and Race Equality in Brazil: A Discussion of Public Employment Policy}

The article analyzes public policies for promoting equal employment opportunities in terms of race and gender in Brazil, with a double focus. First, seeking to reclaim the historical perspective in the policies' implementation, considering the difficulties they have encountered; second, through reflections on the policies' limits and potentialities. Since such policies have only been implemented recently in Brazil, the article focuses especially on how Federal government planning for 2004-2007 and 2008-2011 has dealt with gender and race inequalities.

Key words: gender equality; race equality; work market

\section{RÉSUMÉ}

Égalité de Genre et de Race au Brésil: Une Discussion sur la Politique Publique de l'Emploi

Dans cet article, on examine les politiques publiques promouvant l'égalité des chances de genre et de race au Brésil, concernant le domaine de l'emploi, à partir d'une double optique. D'un côté, en cherchant à reconstituer la perspective historique de leur processus d'implantation, compte tenu des difficultés qu'elles ont rencontrées pour y être reconnues, de $\mathrm{l}^{\prime}$ autre, au moyen $\mathrm{d}^{\prime}$ une réflexion sur leurs potentiels et limites. Tout en considérant la courte période de mise en place de ces politiques au Brésil, une attention particulière est apportée à la la façon dont la question des inégalités de genre et de race est traitée par le Plan au gouvernement fédéral dans ces périodes de 2004-2007 et 2008-2011.

Mots-clé: égalité de genre; égalité de race; marché du travail 